\title{
UM ESTUDO SOBRE A FORMAÇÃO POLÍTICA DE PROFESSORES DE EDUCAÇÃO FÍSICA'
}

\author{
MS. GUILHERME GIL DA SILVA \\ Mestre em Ciências do Movimento Humano pela Universidade Federal do Rio Grande do Sul \\ (UFRGS), Professor na Rede Pública do Estado do Rio Grande do Sul \\ (Porto Alegre - Rio Grande do Sul - Brasil) \\ Email: guilermegil@gmail.com \\ DR. VICENTE MOLINA NETO \\ Doutor em Filosofia e Ciências da Educação pela Universidade de Barcelona (Espanha), Professor \\ titular na Universidade Federal do Rio Grande do Sul \\ (Porto Alegre - Rio Grande do Sul - Brasil) \\ Email: vicente.neto@ufrgs.br
}

\begin{abstract}
RESUMO
Este estudo analisa como se articulam os elementos que contribuem para a formação política de professores de Educação Física, engajados em diferentes instituições onde esta formação acontece. Partiu-se da seguinte questão investigativa: como se dá a formação política de professores de Educação Física engajados em diferentes lutas sociais? Realizamos seis entrevistas e as analisamos à luz da produção do conhecimento sobre o objeto de estudo da formação política de professores e de uma avaliação sobre aspectos conjunturais da sociedade, da escola, da Educação e da Educação Física. Interessou-nos explorar a questão de como o sentido político da Educação se expressa na teoria e na prática entre esses professores.
\end{abstract}

Palavras-chave: Educação Física; formação de professores; formação política; produção do conhecimento.

1. Para a realização desta pesquisa os autores contaram com financiamento da CAPES (Programa de Fomento à Pós-Graduação) e do CNPq (Produtividade em Pesquisa, nível 2), respectivamente. 
Neste artigo analisamos o tema da formação política na Educação Física a partir de entrevistas realizadas com professores engajados em sindicatos, movimentos sociais, direções de escolas e parlamento municipal em Porto Alegre, Rio Grande do Sul. O objetivo central da pesquisa foi analisar como se articulam os elementos que compõem a formação política de professores de Educação Física engajados em diferentes instituições onde esta formação acontece. Os seus resultados permitem a sua compreensão a partir de três categorias-chave: prática social, relações familiares e formação inicial.

nosso ponto de partida são os professores em sua atividade política e o ponto de chegada é a formulação de uma explicação sobre a formação política desses professores. Nessa trilha, procuramos apontar as contradições neste movimento, que sirvam de ponto de partida para superações e novas sínteses, algo que não cessa com esta pesquisa. Nesse sentido, realiza-se também a crítica do real levantando possibilidades tanto para a produção teórica, quanto para a ação prática na formação política de professores de Educação Física.

A hipótese central da pesquisa se refere ao fato de que não predomina, nos cursos de formação inicial em Educação Física, a ênfase à formação política dos professores, mas sim, à sua formação para o trabalho docente. Assim, foram realizadas entrevistas à luz da produção do conhecimento sobre o objeto de estudo e de uma avaliação sobre aspectos conjunturais da sociedade, da escola, da educação e da Educação Física. Ou seja, interessou-nos explorar a questão de como o sentido político da educação se expressa na teoria e na prática entre esses professores.

Situamo-nos entre os principais debates, discussões e formulações produzidas por estudiosos do objeto da formação política de professores e procuramos evidenciar na realidade como isso se expressa. As discussões apresentadas neste artigo expõem os resultados de nossa pesquisa em forma de conclusão-síntese.

Há vinte anos, duas dissertações de mestrado vinham a público apresentando resultados de pesquisas sobre "a formação política do professor de Educação Física". (RUBIN, 1987; FERREIRA NETO, 1989). De um ponto de vista mais geral, esses autores se posicionavam ao lado das pesquisas que se apresentam como avanços para a área, no sentido de confrontar as posições conservadoras do período da ditadura civil-militar - o que eles mesmos declaram como uma "abordagem crítica". (RUBIN, 1987, p.2; FERREIRA NETO, 1989, p.6). Ao mesmo tempo, ambos argumentavam a favor da "transformação social" (FERREIRA NETO, 1989, p.6 passim; RUBIN, 1987, p. I 3 passim), o que permite considerar que, para além de avanços do ponto de vista científico, procuravam formular suas pesquisas em direção a novas perspectivas para a sociedade no seu conjunto. 
A polêmica que esperamos reinaugurar tem também a intenção de responder a uma pergunta do tempo histórico que vivemos: seria possível dizer que as lutas da atual conjuntura, das quais participam os professores de Educação Física, expressam as mesmas possibilidades de alteração da correlação de forças, ou seja, representam alterações significativas para a sociedade no seu conjunto, ou são apenas lutas específicas e intestinas a essa área? A Educação Física brasileira ainda tem se perguntado sobre a possibilidade da transformação social? Se em um determinado período da história brasileira vislumbrava-se a possibilidade da superação de uma realidade adversa aos professores de Educação Física e se produziram conhecimentos que apontavam a direção da superação dessa problemática, o que teríamos a dizer hoje?

Como fundamentação teórica para uma compreensão sobre o conceito de política, do ponto de vista da teoria do conhecimento em que nos ancoramos para a realização desta pesquisa, fazemos referência à tese da "negatividade da política" que, segundo Lessa (2007), Bianchi (2007) e Boron (2003), é como o conceito é tratado na perspectiva marxista. Segundo essa formulação, a abolição da política significa também a abolição de outras relações sociais que com ela se fundaram, entre elas o Estado e a propriedade privada. Nesses termos, se colocam os fundamentos de uma possibilidade para o futuro da humanidade, ou seja, com o fim das relações desumanizantes da sociedade capitalista, podem se fundar outras relações (novas, completamente diferentes das anteriores), que serão as de uma sociedade socialista/comunista.

\section{PROCEDIMENTOS PARA ANÁLISE DAS INFORMAÇÕES}

Foram coletados depoimentos de seis professoras e professores de Educação Física, tomados como representações do real, ou seja, uma dentre outras possibilidades de apreender a realidade. Contudo, entendemos que o fenômeno da formação política de professores de Educação Física, para ser melhor apreendido, necessitaria ir além do que somente estas representações. ${ }^{2}$

roteiro para as entrevistas procurou contemplar como questões quatro aspectos centrais, sendo eles: (a) questões para identificação do professor; (b) questões sobre a formação inicial na Educação Física; (c) questões sobre o trabalho desempenhado; (d) questões sobre a compreensão acerca da política. Optamos pela realização de entrevistas semi-estruturadas, considerando suas possibilidades (TRIVIÑOS, 1987, p. I46), o campo empírico com o qual lidamos e os objetivos da investigação.

2. Esta tarefa é empreendida por Silva (2009). 
Em grande medida, se trataram as entrevistas realizadas como depoimentos ou relatos das histórias de vida desses professores de Educação Física. (GOODSON, 2004). Entendemos esta como uma ferramenta privilegiada para análise e interpretação, na medida em que incorpora experiências subjetivas aliadas aos contextos sociais. De modo geral, os autores que tratam sobre a história de vida a concebem como um instrumento para dar voz ao silenciado, ao anônimo. (MENEGHEL, 2007; PAULILO, 1999; BETI; MIZUKAMI, 1997). A história de vida se situa no quadro amplo da história oral, em que também estão depoimentos, entrevistas, biografias, autobiografias, etc. e fornece uma base consistente para o entendimento do componente histórico dos fenômenos individuais, assim como para a compreensão do componente individual dos fenômenos históricos. (PAULILO, 1999).

Com relação a esses instrumentos de pesquisa, ressalta-se que também têm sido utilizados pelos pesquisadores do Grupo de Pesquisas Qualitativas Formação de Professores e Prática Pedagógica em Educação Física e Ciências do Esporte (F3P-EFICE), que tem procurado reunir um conjunto de procedimentos metodológicos que unifiquem as análises, constituindo um corpo teórico mais coeso. (WITTIZORECKI et al., 2006; NUNES; MOLINA NETO, 2005). No caso do presente texto, experiências já acumuladas relacionam essa ferramenta com as adotadas por lasi (2006) sobre os relatos de trajetórias de militantes políticos como uma interessante referência para nos situar no campo de análise.

\section{A DEFINIÇÃO DAS INSTITUIÇÕES A SEREM CONSIDERADAS PARA A BUSCA DOS ENTREVISTADOS}

O ponto de partida da pesquisa, como referido, é o resultado ou produto da formação política dos professores entrevistados, ou seja, a luta, o engajamento, a militância dos professores. Isso significa que os colaboradores da pesquisa foram definidos pelo seu engajamento em diferentes instituições, mas é necessário referir que a chegada aos professores não se deu a partir de quem fossem ou representassem na "política", mas do que representam socialmente as instituições das quais fazem parte.

Partiu-se da ideia de que há entre o professorado de Educação Física o compartilhamento de certas "crenças" em relação ao seu trabalho e na cultura escolar, baseado nos estudos de Molina Neto (2003). É o que se expressa, por exemplo, pelas "crenças" "do pouco valor da atividade docente", "do professor diferente", "das finalidades educativas distintas" e "de um modelo de professor necessário para a escola pública”. (MOLINA NETO, 2003, p. I 52). Segundo o autor, a participação política do professorado de Educação Física é bastante relevante na escola pública, 
e se dá em dois âmbitos relacionados entre si: a administração escolar e a relação com os alunos.

A ampla liberdade relativa de que dispõem para atuar, o fato de trabalhar de acordo com
suas preferências pessoais, a programação de ensino pouco sistematizada e uma relação
muito próxima com o aluno oferecem aos professores de educação física possibilidades de
ocupar um espaço político privilegiado na cultura da escola. (MOLINANETO, 1998, p. 40).

Seria correto, então, afirmar que os professores de Educação Física ocupam cargos de direção como os mencionados porque são professores diferenciados dos demais na escola? Assim, nossa intenção inicial era de contar com a colaboração de professores que efetivamente estivessem engajados em sindicatos, direções de escolas, movimentos sociais e no parlamento. Procuramos, com isso, contemplar diferentes instituições sociais onde a formação política é exigida e acontece. Assim, a primeira instituição que foi mapeada foi a escola, atendendo a uma demanda por contribuir com o conjunto de estudos que vêm sendo realizados junto à Rede Municipal de Ensino de Porto Alegre (RMEPA) e considerando os dados que expõem que quase um quarto das direções destas escolas (22,5\%) e um décimo (I0\%) das vice-direções neste município era ocupada por professores de Educação Física. (MOLINA NETO, 1998).

Outra instituição foi o parlamento municipal, devido à presença de vereadores, no município de Porto Alegre, que realizaram sua formação inicial em Educação Física. Talvez mais explicitamente nesta instituição, uma instância do Estado, se revela um lugar onde está presente a formação política de quem o ocupa, seja como uma preparação para lá chegar, seja durante a sua permanência aí. Assim, a Câmara de Vereadores de Porto Alegre é a instituição parlamentar definida como contribuição para a pesquisa.

Ainda outra instituição são os movimentos sociais de luta (D'AGOSTINI, 2008) e, por expressar um histórico de lutas e enfrentamentos na área da Educação Física e representar uma importante esfera para a militância de seus professores, foi definido o Movimento Nacional Contra a Regulamentação do Profissional de Educação Física (MNCR) como componente do universo de análise. Por fim, outra instituição é o sindicato, sendo que no município foram mapeados pelo menos cinco deles com representação de professores de Educação Física ou os mesmos engajados em alguma de suas instâncias como dirigentes. A fim de dar conta da maior abrangência possível do engajamento sindical de professores, mapearam-se sindicatos de atuação municipal, estadual e nacional, todos com sede na cidade. ${ }^{3}$

3. Tratam-se da Associação dos Trabalhadores em Educação do Município de Porto Alegre (ATEMPA), do Centro de Professores do Estado do Rio Grande do Sul (CPERS), do Sindicato dos Profissionais de Educação Física do 
Abaixo é apresentado um quadro que sintetiza informações sobre as professoras e professores que foram entrevistados, a instituição à qual se vinculam e onde realizaram sua formação inicial, além dos períodos de experiência docente e de engajamento na função que motivou-nos a entrevistá-los.

Quadro I. Informações sobre os professores por ordem de entrevista

\begin{tabular}{|c|c|c|c|c|c|c|}
\hline NOME & FUNÇÃO & INSTITUIÇÃO & $\begin{array}{l}\text { FORMAÇÃO } \\
\text { INICIAL }\end{array}$ & $\begin{array}{c}\text { OUTRA } \\
\text { FORMAÇÃO }\end{array}$ & $\begin{array}{l}\text { EXPERIÊNCIA } \\
\text { DOCENTE }\end{array}$ & $\begin{array}{l}\text { ENGAIA- } \\
\text { MENTO } \\
\text { POLÍTICO }\end{array}$ \\
\hline Professor I & $\begin{array}{l}\text { Militante de } \\
\text { movimento } \\
\text { social }\end{array}$ & MNCR & UFRGS & $\begin{array}{l}\text { Doutorado/EF } \\
\text { (em curso) }\end{array}$ & 4 anos & 2 anos \\
\hline Professor 2 & Sindicalista & ANDES-SN & UFPEL & $\begin{array}{l}\text { Especialista/EF; } \\
\text { Mestre/EF }\end{array}$ & 25 anos & 3 anos \\
\hline Professora 3 & Sindicalista & ATEMPA & IPA & Especialista/EF & 22 anos & 2 anos \\
\hline Professora 4 & $\begin{array}{l}\text { Diretora de } \\
\text { escola }\end{array}$ & $\begin{array}{l}\text { Escola } \\
\text { Municipal }\end{array}$ & UFRGS & Especialista/EF & II anos & 2 anos \\
\hline Professora 5 & Vereadora & $\begin{array}{l}\text { Câmara de } \\
\text { Vereadores de } \\
\text { Porto Alegre }\end{array}$ & UFRGS & $\begin{array}{c}\text { Magistério; } \\
\text { Especialista/EF }\end{array}$ & $\begin{array}{c}8 \text { anos (até } \\
1991 \text { ) }\end{array}$ & 9 anos \\
\hline Professora 6 & $\begin{array}{l}\text { Diretora de } \\
\text { escola }\end{array}$ & $\begin{array}{l}\text { Escola } \\
\text { Municipal }\end{array}$ & IPA & $\begin{array}{l}\text { Especialista/EF; } \\
\text { Bacharel em } \\
\text { Direito }\end{array}$ & 30 anos & 5 anos \\
\hline
\end{tabular}

Para os fins de nossa pesquisa, consideramos como período de "experiência docente" o tempo compreendido desde o ano de formatura dos professores até o momento das entrevistas. No caso da Professora 5, a partir de seu depoimento ela mesma deixa explícito que sua experiência docente foi interrompida desde que assumiu integralmente demandas sucessivas no sindicato, na secretaria de educação e no parlamento municipal; por isso ela é a única cuja contagem deste tempo se interrompe. Já o período de "engajamento político" diz respeito ao tempo de engajamento na atual função, ou seja, na instituição a que os professores estavam vinculados no momento em que se realizou a pesquisa. Se fosse recuperada a história de vida de cada um dos colaboradores, veríamos que esse período se estenderia em todos os casos, já que todos tiveram experiências anteriores em outras instituições ou lutas políticas e, de acordo com os relatos, o seu engajamento iniciou anteriormente a estes atuais vínculos.

Rio Grande do Sul (SINPEF-RS), do Sindicato de Professores da Rede Privada do Rio Grande do Sul (SINPRO) e do Sindicato Nacional dos Docentes das Instituições de Ensino Superior (ANDES-SN). À exceção do SINPEFRS, todos os demais têm pelo menos vinte anos de história de lutas, reunindo professores de diferentes áreas, inclusive da Educação Física. 


\section{A ANÁLISE DAS ENTREVISTAS E A BUSCA DAS CATEGORIAS DE CONTEÚDO}

A partir da coleta e análise dos depoimentos pudemos chegar às categorias de conteúdo com as quais demos o trato da pesquisa realizada. Dessa maneira, compõem a nossa análise as categorias que foram mais relevantes encontradas na pesquisa empírica. Procurando articular as informações obtidas a partir dos depoimentos dos professores com as discussões realizadas sobre as referências teóricas, analisou-se o aspecto da formação política a partir dos principais temas que sobressaíram nas entrevistas, tratados à luz das categorias do método como categorias de conteúdo (KUENZER, 1998).

A análise das informações revelou temas que se evidenciaram menos relevantes. Estes temas foram reunidos em torno das seguintes categorias: "conjuntura social”, "conjuntura política”, "projeto histórico", "concepção de política”, "concepção de Educação Física", "forma de consciência", "necessidade", "trabalho". Além desses temas, com mais ênfase e expressando uma capacidade de síntese dos demais, as seguintes categorias centrais, mais relevantes, se evidenciaram, e com elas passamos a lidar para a análise: "prática social", "relações familiares" e "formação inicial". Entende-se, portanto, que estas três categorias são aquelas que reúnem as informações trazidas pelos colaboradores e auxiliam na aproximação de uma resposta ao problema de pesquisa e ao alcance de seus objetivos, tendo sido a partir delas que se procedeu à análise que seguirá na próxima seção.

\section{PRÁTICA SOCIAL, RELAÇÕES FAMILIARES E FORMAÇÃO INICIAL: CATEGORIAS-CHAVE PARA COMPREENSÃO DA FORMAÇÃO POLÍTICA DE PROFESSORES DE EDUCAÇÃO FÍSICA}

Analisando as informações obtidas com a pesquisa empírica realizada, caracterizamos as professoras e professores depoentes na pesquisa. Além das informações sobre suas trajetórias na "política" (questões familiares, sua chegada ou ingresso na política e no trabalho que atualmente exercem, etc.), fez-se também a análise mais detida sobre a formação e o engajamento político, procedendo à triangulação dos dados para estabelecer relações entre a teoria que nos fundamenta, a conjuntura e a investigação empírica, umas subsidiando e articulando-se às outras.

Pudemos concluir que a formação política dos professores de Educação Física que estão engajados nos diferentes locais se dá de forma diferenciada em muitos aspectos. A se considerar os depoimentos dos professores, nota-se que aqueles que trabalham na direção de escolas tratam de problemas diferentes dos que se 
enfrentam no parlamento, nos sindicatos, nos movimentos sociais. Evidentemente que esta era uma situação esperada e, portanto, não nos causou maiores surpresas.

A prática social - as condições materiais e objetivas da vida - sobressaiu nas representações dos professores. Sem pretender que isso expresse uma perspectiva totalizante ou generalizante, nota-se que de alguma forma os professores, em algum momento de suas trajetórias, se viram imperativamente forçados a engajar-se na política, tal como expressa a passagem a seguir:

Só que com isso, o que acontece, eu entrei sabendo que eu não iria pra linha de frente de início. Mas a situação do dia-a-dia ela te impõe isso, né, de que às vezes não tem outra pessoa, não tem, tu vai ter que ir lá (Professora 3 , sindicalista).

Vianna ( 1999 ) discute o caráter prioritário da militância de professores, o que ela trata como o predomínio de um "modelo sindical" na militância docente. Sua pesquisa traz elementos para a compreensão de que para muitos professores, a militância política passa a ser uma necessidade quase que vital, o que os leva a uma dedicação exclusiva às tarefas e demandas do seu engajamento.

Os exemplos evidenciaram essas relações, seja nos casos de professores que foram "empurrados" a serem os representantes de projetos ou causas coletivas (Professora 4 e Professora 6), seja no de questões que viam como importantes, mas que ao mesmo tempo não vislumbravam a possibilidade de outros indivíduos as assumirem, ficando sozinhos em situações que os levavam a assumirem posições de lideranças ou direção dos processos (Professor I, Professora 3 e Professora 5).

Eu entrei por que, justamente por falta da composição. Porque meu trabalho sempre, ele no grupo e na construção, é um trabalho de bastidor. Então não é um trabalho de frente, é um trabalho de bastidor. E eu não me importo de fazer esse trabalho de bastidor, porque eu não gosto muito dessa exposição. E aí como é que se deu, se deu porque a pessoa faltou, faltaram pessoas que, enfim... Porque na hora que tu vai compor uma chapa, tu precisa também desse trabalho técnico, tu precisa dum trabalho do conhecimento daquela pessoa, da capacidade delas de botar em ação algumas coisas. Então nem sempre é aquela pessoa que vai falar numa assembleia, né. Tem no grupo pessoas com tais perfis que tu sabe que, bom, e aí, nisso que eu entrei. (Professora 3, sindicalista).

Isso também se visualiza nos casos relatados de professores que, ao se depararem com situações em seus trabalhos tais como as greves, por exemplo, abre-se uma possibilidade tanto para compreender os processos de injustiça, exploração, desigualdade, etc. (Professora 3 e Professora 4), quanto para, identificando-se com outros colegas na mesma situação, vislumbrarem a possibilidade da ação coletiva (Professor 2 e Professora 5). 
Era o documento da nomeação, pra tomar posse - eu cheguei na escola, encontrei o vice-diretor [ . . . ] entreguei o "fono", atravessei o pátio e fui pro auditório, porque havia uma assembléia dos municipários, que reunia professores e todos os servidores da Prefeitura, e a proposta era greve. Eu entreguei o "fono" e entrei em greve na mesma manhã (Professor 2, sindicalista).

Além dessas situações, também é possível referir o fato de que muitas vezes a "formação política" se dá na própria prática, ou seja, no engajamento e com a participação nas atividades, manifestações, assembleias (Professor I e Professor 2), na formulação de planos e projetos, na responsabilização pelas tarefas e demandas (Professora 3 e Professora 4), enfim, não havendo qualquer menção a cursos, receituários, atividades de formação anteriores à própria prática militante. São as situações eminentemente práticas e objetivas que direcionam a tomada de posição e a ação subjetivas ou a transição de níveis menos elevados a mais elevados de consciência política. (IASI, 2006).

É o desvelamento da realidade o que caracterizaria este momento, a partir do qual imperiosamente a busca por alterações emerge a um primeiro plano. Há, segundo esse ponto de vista, uma situação em que o indivíduo, ao deparar-se com a realidade, não é capaz de visualizá-la em sua totalidade, não vendo com clareza os problemas por que passa ou então avaliando que eles são irremediáveis, naturais.

\footnotetext{
Um processo de desalienação primária assim, né. [ . . . ] Mas é quando tu começa a identificar na prática a contradição. Quando tu começa a ver que o mundo não precisa ser... nem sempre foi assim, e nem sempre precisa ser assim, né. Aí tu começa a identificar que, bom, se a história mostra que o mundo "tá" em constante movimento e que ele muda e transforma o tempo todo, talvez seja nosso papel também continuar esse processo de transformação do mundo (Professor I, militante de movimento social).
}

Essa situação estaria próxima da "primeira forma de consciência". (IASI, 2007). Assim, é em um processo de "desalienação" ou em uma "segunda forma de consciência" (IASI, 2007) - a consciência política reivindicatória - que se abre a possibilidade para o engajamento político.

A questão das relações familiares também esteve presente fortemente em nossas entrevistas. Visualizou-se que essa interferência vai desde o incentivo para o ingresso no curso de Educação Física (Professora 5), passando pelas conversas e ensinamentos corriqueiros até as próprias condições objetivas de acesso ou apropriação de determinados produtos ou informações sobre a realidade social (Professor I, Professor 2 e Professora 3). Uma família que "conversa sobre política" ou que tem um de seus indivíduos participante em atividades que se relacionem a greves, manifestações, etc., potencializa, pelo seu exemplo, o desenvolvimento 
da consciência de outros indivíduos, que poderão vir a também se engajar com a política (Professor I e Professora 6).

Não se pode desprezar também que as relações familiares expressam as relações mais gerais da sociedade, e nos relatos que se seguiram sobre o velamento das condições sociais do período da ditadura civil-militar brasileira, por exemplo (Professor 2 e Professora 4), é necessário compreender que mesmo que não fosse intencionalmente, ou seja, no preciso sentido de uma forma alienada (MÉSZÁROS, 2006), nesse caso as famílias não promovem o desvelamento da realidade, perpetuando essa alienação.

Então, pra ter uma ideia, eu tenho até hoje guardado o exemplar número I da Revista Veja, que a capa dela era uma capa vermelha com a foice e o martelo - símbolo da Terceira Internacional - estampado na capa - inteira, assim. Essa revista eu só fui ver lá pelos anos... 89... quando meu pai se mudou da casa onde a gente morava e eu retornei pra ocupar aquela casa, pra morar naquela casa. Mas aí ficaram lá todos os pertences que eram do meu pai, da minha mãe, dos meus irmãos. E eu comecei a vasculhar e a arrumar. Um dia abro um baú, que na verdade era uma cama, e achei coisas antiquíssimas, entre elas a Revista Veja com essa capa. Então... meu pai nunca nos mostrou essa revista, entende? Era uma coisa, imagina, era uma revista comunista! Então isso era, na nossa formação familiar também não se discutia isso... meu avô tinha sido militar [...] meu pai tinha simpatia também pelos militares. Então a formação familiar já não contribuiu no sentido de que a gente fosse desvendando aquilo que tava acontecendo. Não se falava disso. Absolutamente não se falava: a imprensa não falava, a televisão não falava. A televisão passava em horário nobre, por exemplo, a abertura das Olimpíadas do Exército (Professor 2, sindicalista).

A partir das entrevistas realizadas, se evidenciou também que a compreensão sobre a formação política não pode ser restringida aos cursos de formação inicial em Educação Física. Alguns colaboradores mencionaram professores que julgam terem sido responsáveis por incutir-lhes uma visão crítica em relação à sua concepção de Educação Física (Professor 2 e Professora 3). Da mesma forma, houve impressões sobre o fato de que o ingresso na Universidade proporcionou o contato com variadas atividades que somaram à sua formação, entre as quais estão eventos, congressos, cursos realizados, que permitiram conhecer realidades e discussões que não encontraram em seus cursos (Professor I, Professor 2 e Professora 5 e Professora 6).

Também é na vida universitária que tomam contato com locais como as casas de estudantes, por exemplo, onde a vivência com outros indivíduos que compartilham da mesma situação de dependência das políticas de assistência estudantil permitem a identificação coletiva (Professora 5). Mais ainda, o próprio mundo do trabalho, que os levou, pela experiência profissional com a Educação Física a relações que impulsionaram o seu engajamento político (Professor 2, Professora 4 
e Professora 6), da mesma forma quando se identificam com outros professores e trabalhadores que vivenciam relações de exploração (Professor 2 e Professora 5), ou mesmo visualizando relações de desigualdade e miserabilidade dos públicos com os quais trabalhavam (Professora 3 e Professora 4).

[... ] a primeira formação política - impacto político mesmo - foi a Casa do Estudante, não foi a ESEF. Então na ESEF eu não lembro de movimento estudantil e de coisas que tenha me envolvido lá. Assim: era a técnica, era a discussão... [...] comecei a ir nos Encontros de Educação Física, e na época, a grande discussão era "qual a identidade da Educação Física?", "Educação Física cuida do corpo e mente” (Professora 5, vereadora).

Em suma, ainda que não tenham sido relatadas experiências efetivamente curriculares na formação inicial dos professores que interpelamos, o simples ingresso na educação superior e as vivências que isso proporciona pareceram fortemente influenciar na sua formação política.

Por fim, é possível considerar o universo empírico que foi alcançado pela pesquisa, para algumas afirmações. Há indicações e apontamentos que podem acenar uma possibilidade transcendente da formação política em direção à compreensão da tese da "negatividade", como referido anteriormente, analisando os casos de professores com os quais tivemos contato e relacionando-os a alguns pressupostos com os quais lidamos a partir da teoria orientadora da pesquisa.

\section{CONSIDERAÇÕES FINAIS}

Entendemos que a conjuntura que se tem atualmente no que toca a formação política, aqui em análise, se expressa, por exemplo, com o levante dos estudantes que ocupam prédios públicos e ruas em manifestação, as pesquisas voltadas a responderem sobre a articulação de professores com as lutas sociais, os diferentes movimentos sociais de luta da classe trabalhadora que se organizam, os enfrentamentos anti-sistêmicos contra o braço fiscalizador do Estado na figura do sistema Confef/Crefs, entre outros tantos elementos. Isso denota uma conjuntura favorável não só para o estudo, mas também para a efetivação de uma formação política na Educação Física, e traz muitos elementos para a nossa análise, embora talvez não signifique perspectivas de alteração na correlação de forças na sociedade em seu todo.

Não desprezando as trajetórias de luta e combatividade em diferentes níveis e no trabalho em locais tão diversos, ao recuperar as histórias de vida de professores de Educação Física, e como chegaram aos lugares em que hoje estão não ficam evidentes a participação em atividades formativas que os permitisse compreender a 
gênese e a tarefa da superação (abolição) da política. Ressaltamos que em nenhum momento se tinha a expectativa de que os professores fossem estudiosos da política, já que a própria atividade prática, como se viu pelos diversos exemplos trazidos, é a bússola para a sua consciência militante. Um questionamento que seria possível, diante desse quadro, é se a luta empreendida por diferentes professores engajados em diferentes instituições sociais, como se procurou considerar, aponta a direção da superação das relações sociais desumanizantes impostas pela exploração capitalista. Nesse sentido é que acreditamos ser possível avaliar de que perspectiva se dá o engajamento dos professores na política.

De acordo com as discussões que aqui foram trazidas, que se articulam com elementos da conjuntura social e com a teoria que nos fundamenta, procurou-se evidenciar a necessidade do trato com o objeto da formação política. O desafio final, se bem entendemos o fazer científico, é fazer com que o debate in stricto sensu aqui recolocado ultrapasse este limite, chegando, quem sabe, à luta social concreta pela materialização desta via.

A resposta à questão central que moveu a presente pesquisa situa-se entre três elementos que pareceram relevantes a partir dos casos concretos que foram analisados: há uma multiplicidade de determinações da prática social, das relações familiares e da formação inicial que se sintetizam e contribuem para a formação política de professores de Educação Física.

É possível supor que o maior engajamento político de professores de Educação Física é expressão do acirramento da polarização da luta de classes na sociedade e que a sua formação política é condição necessária, mas não suficiente, para que este mesmo engajamento se dê em uma perspectiva de classe para si (expressão de uma consciência revolucionária), ou seja, de lutas coletivas em torno das reivindicações docentes juntamente aos demais trabalhadores. Além disso, vimos que a formação política de professores ancorada na perspectiva da transformação social é concomitante a um desenvolvimento de formas mais elevadas de consciência política desses indivíduos.

\section{A study about the political formation of Physical Education teachers}

ABSTRACT: This study aimed to ascertain how is the articulate of the elements that contribute to the political formation of Physical Education teachers engaged in various institutions where this happens. We start with the following investigative question: how is the political formation of Physical Education teachers engaged in various social struggles? We conducted six interviews and analyzed them in light of the knowledge production about the object of study teachers' political formation and an evaluation of conjunctural aspects of society, school, education 
and Physical Education. Interested in exploring the question of how the political meaning of education is reflected in theory and practice among these teachers.

KEYWORDS: Physical education; teachers' formation; political formation; knowledge production.

\section{Um estudio sobre la formación política de profesores de Educación Física}

RESUMEN: Este estudio analiza como se articulan los elementos que contribuyen para la formación política de profesores de Educación Física empleados en diferentes instituciones adonde esta formación se sucede. La investigación inició con la siguiente cuestión: ¿cómo se da la formación política de profesores de Educación Física que participan en distintas luchas sociales? Realizamos seis entrevistas y las analizamos bajo la luz de la producción del conocimiento acerca del objecto de estudio formación política de profesores y de una evaluación sobre aspectos conjunturales de la sociedad, de la escuela, de la educación y de la Educación Física. Interesó explotar la cuestión de cómo el sentido político de la educación se expresa en la teoría y la práctica entre esos profesores.

PALABRAS-CLAVE: Educación física; formación de profesores; formación política; producción de conocimiento.

\section{REFERÊNCIAS}

BETTI, I. C. R.; MIZUKAMI, M. G. N. História de vida: trajetória de uma professora de educação física. Motriz, Rio Claro, v. 3, n. 2, p. 108 - II 5, dez. 1997.

BIANCHI, A. Uma teoria marxista do político? o debate Bobbio trent'anni doppo. Lua Nova, São Paulo, n. 70, p. 39-82, 2007.

BORON, A. Filosofia política marxista. São Paulo: Cortez; Buenos Aires: CLACSO, 2003.

D'AGOSTINI, A. A educação do MST no contexto educacional brasileiro. 2009. Tese (Doutorado em Educação) - Faculdade de Educação, Universidade Federal da Bahia, Salvador, 2009.

FERREIRA NETO, A. A formação política do professor de Educação Física. 1989. Dissertação (Mestrado em Educação Física) - Universidade Gama Filho, Rio de Janeiro, 1989.

GOODSON, I. F. Historias de vida del profesorado. Barcelona: Octaedro, 2004.

IASI, M. L. As metamorfoses da consciência de classe: o PT entre a negação e o consentimento. São Paulo: Expressão Popular, 2006.

Reflexões sobre o processo de consciência. In: . Ensaios

sobre consciência e emancipação. São Paulo: Expressão Popular, 2007. p. | I -45. 
KUENZER, A. Z. Desafios teórico-metodológicos da relação trabalho-educação e o papel social da escola. In: FRIGOTTO, G. (Org.). Educação e crise do trabalho: perspectivas de final de século. Petrópolis: Vozes, 1998. p. 55-75.

LESSA, S. Lukács: ética e política: observações acerca dos fundamentos ontológicos da ética e da política. Chapecó: Argos, 2007.

LÜDKE, M.; BOING, L. A. O trabalho docente nas páginas de Educação \& Sociedade em seus (quase) 100 números. Educação \& Sociedade, Campinas, v. 28, n. I00, p. | | 79- | 20 |, out. 2007.

MENEGHEL, S. N. Histórias de vida: notas e reflexões de pesquisa. Athenea Digital, Barcelona, n. I2, p. I| 5- |29, 2007.

MÉSZÁROS, I. A teoria da alienação em Marx. São Paulo: Boitempo, 2006.

MOLINANETO, V. A prática dos professores de educação física das escolas públicas de Porto Alegre. Movimento, Porto Alegre, v. 5, v. 9, p. 31-46, 1998.

Crenças do professorado de educação física das escolas públicas de Porto Alegre-RS/Brasil. Movimento, Porto Alegre, v. 9, n. I, p. I 45-169, jan.-abr. 2003.

NUNES, C. F. T.; MOLINA NETO, V. O processo de federalização da ESEF/UFRGS sob a perspectiva dos professores: o estudo de um caso. Movimento, Porto Alegre, v. I I, n. 2, p. 167-189, maio-ago. 2005.

PAULILO, M. A. S. A pesquisa qualitativa e a história de vida. Serviço Social em Revista, Londrina, v. 2, n. I, jul./dez. 1999. Disponível em: http://www.ssrevista.uel.br/c_v2n I_pesquisa. htm. Acesso em: 04 abr. 2010.

PEREIRA, G. R. M. A força das afinidades: estudo sobre a politização do campo educacional brasileiro. Revista Brasileira de Estudos Pedagógicos, Brasília, v. 84, n. 206/208, p. 67-78, jan./dez. 2003.

RUBIN, C. F. A formação política do professor de Educação Física: uma visão gramsciana. 1987. Dissertação (Mestrado em Educação) - Universidade Federal de Santa Maria, Santa Maria, 1987.

SILVA, G. G. Um estudo sobre a formação política na Educação Física. 2009. Dissertação (Mestrado em Ciências do Movimento Humano) - Universidade Federal do Rio Grande do Sul, Porto Alegre, 2009.

TRIVIÑOS, A. N. S. Introdução à pesquisa em ciências sociais: a pesquisa qualitativa em educação. São Paulo: Atlas, 1987.

VIANNA, C. Os nós do "nós": crise e perspectivas da ação coletiva docente em São Paulo. São Paulo: Xamã, 1999. 
- A produção acadêmica sobre organização docente: ação coletiva e relações de gênero. Educação \& Sociedade, Campinas, v. 22, n. 77, p. 100-130, dez. 2001.

WITTIZORECKI, E. S. et al. Pesquisar exige interrogar-se: a narrativa como estratégia de pesquisa e de formação do(a) pesquisador(a). Movimento, Porto Alegre, v. 12, n. 2, p. 9-33, maio/ago. 2006.

Recebido: 01 nov. 2010

Aprovado: 06 jun. 2011

Endereço para correspondência:

Guilherme Gil da Silva

Avenida Ceará, 2060/I02

São Geraldo

CEP 90240-5 I 2

Porto Alegre/RS

E-mail: guilermegi|@gmail.com 